Supplement of Hydrol. Earth Syst. Sci., 25, 1389-1410, 2021

https://doi.org/10.5194/hess-25-1389-2021-supplement

(c) Author(s) 2021. CC BY 4.0 License.

(c) (i)

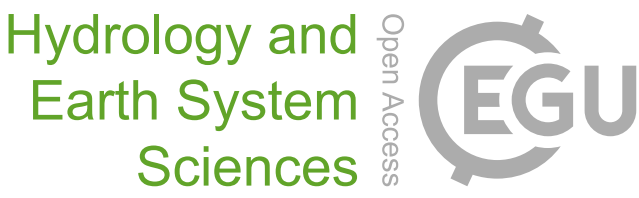

Supplement of

\title{
The value of ASCAT soil moisture and MODIS snow cover data for calibrating a conceptual hydrologic model
}

\section{Rui Tong et al.}

Correspondence to: Rui Tong (tong@hydro.tuwien.ac.at)

The copyright of individual parts of the supplement might differ from the article licence. 


\section{Supplementary}

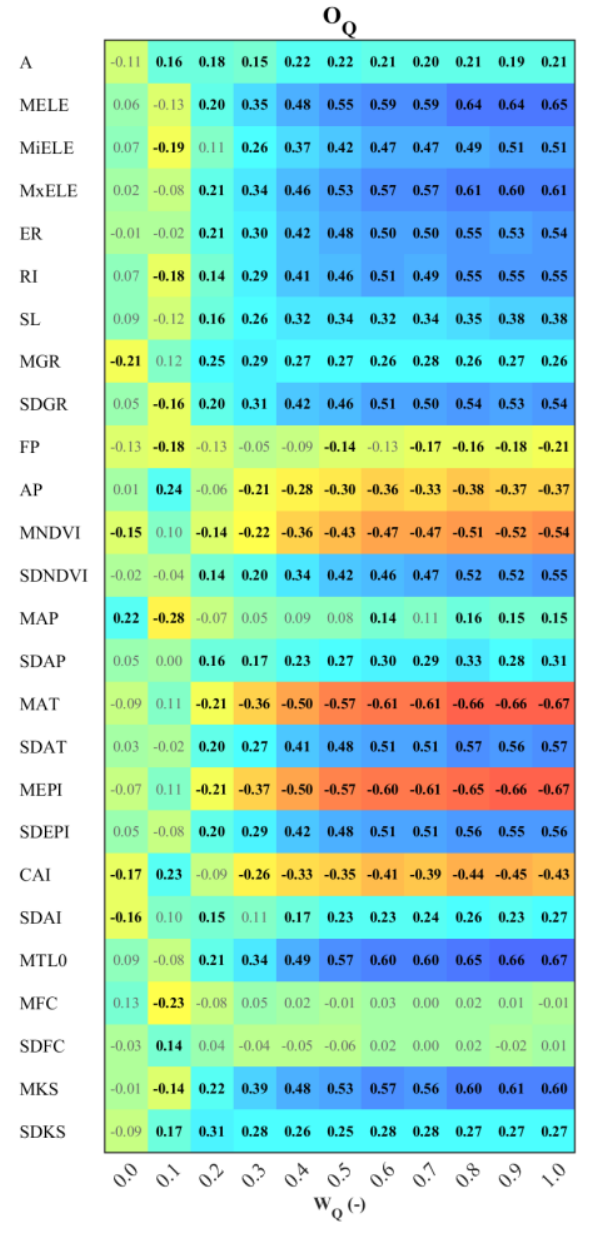

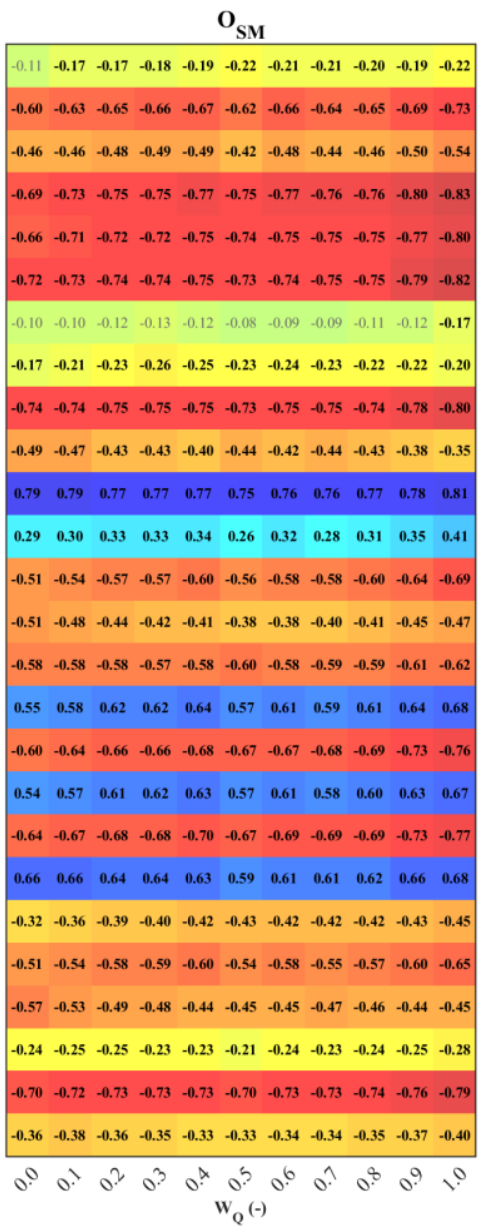

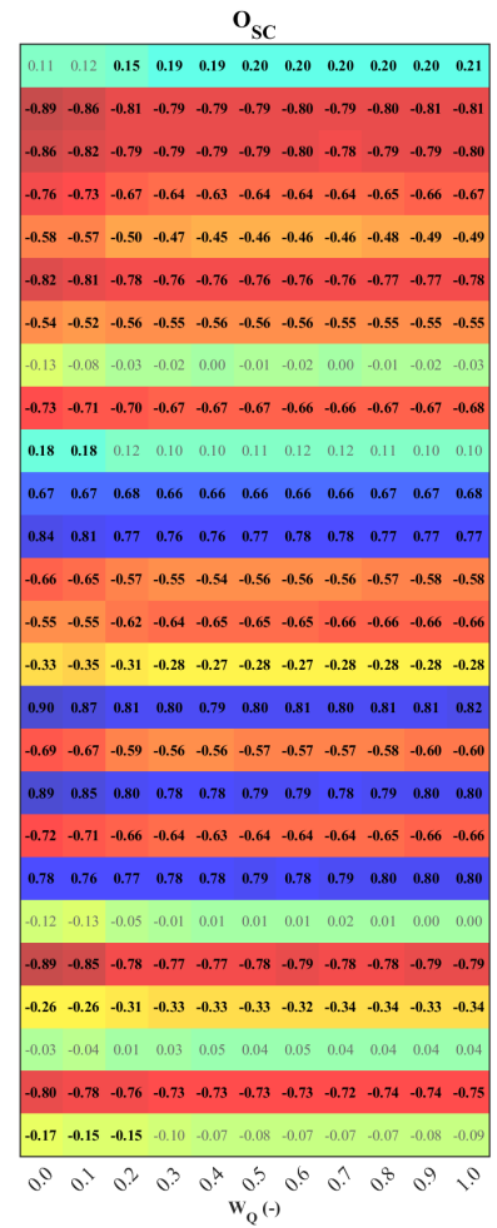

Correlation

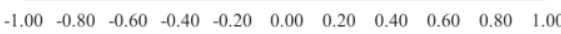

Figure S1: Correlation between catchment attributes (Table 1) and model performance, i.e. runoff (Eq. 2, left panel), soil moisture (Eq. 5, middle panel) and snow cover (Eq. 6, right panel), obtained from multiple objective calibration to satellite soil moisture (ASCAT), satellite snow cover (MODIS) and runoff (Var 3 of Table 4, SSM+SCM+runoff) in the calibration period 2000-2010. Cool and warm colors represent positive and negative correlations, respectively. Bold print indicates significance with p-value lower than 0.05. 


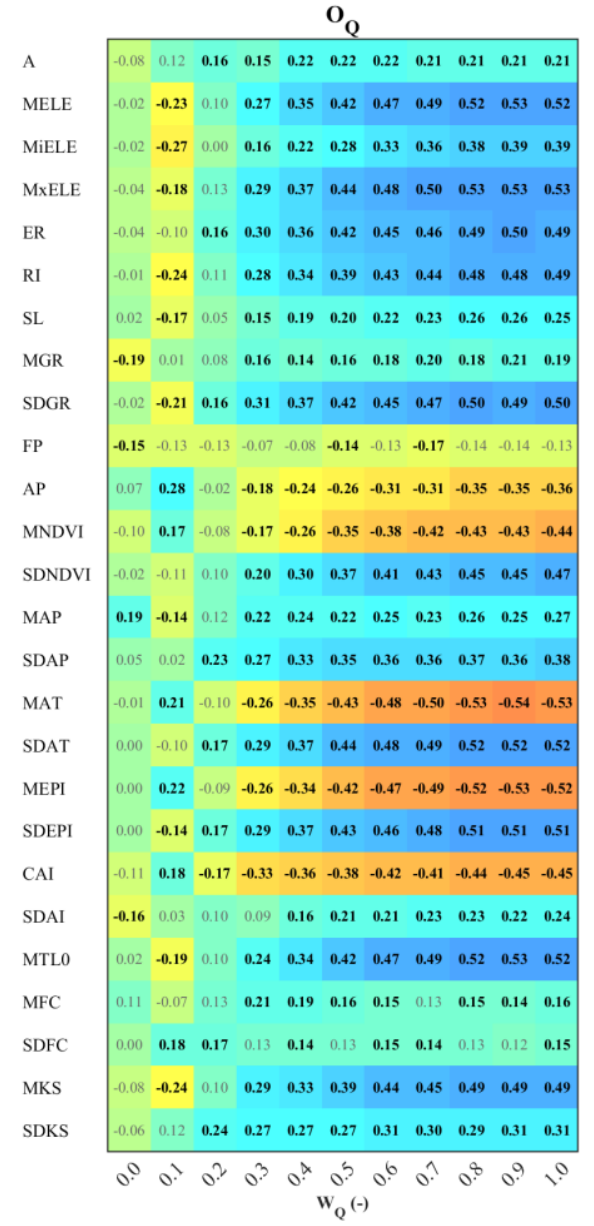

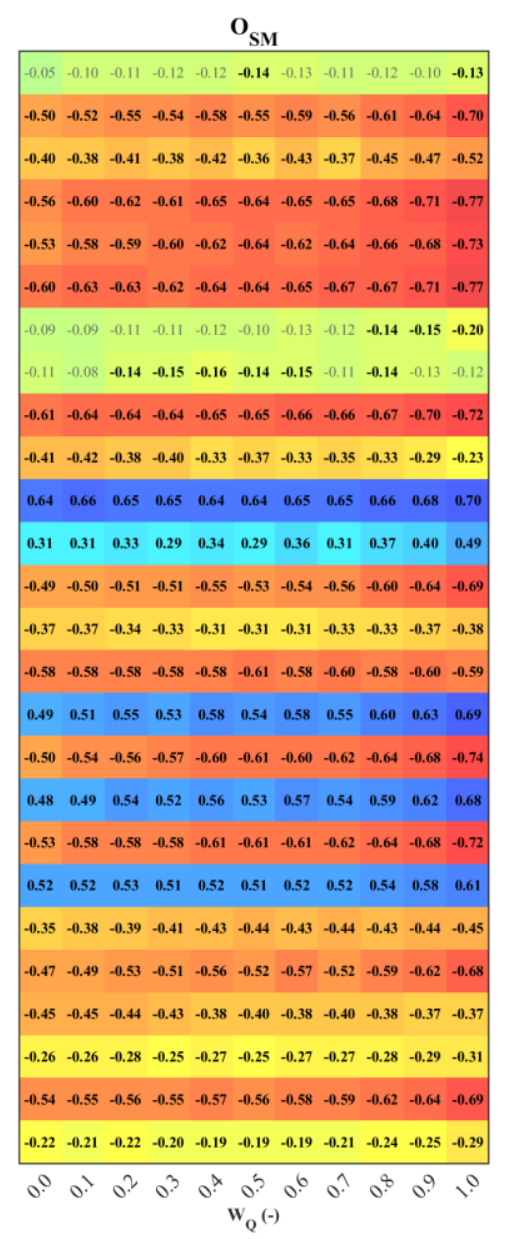

Correlation

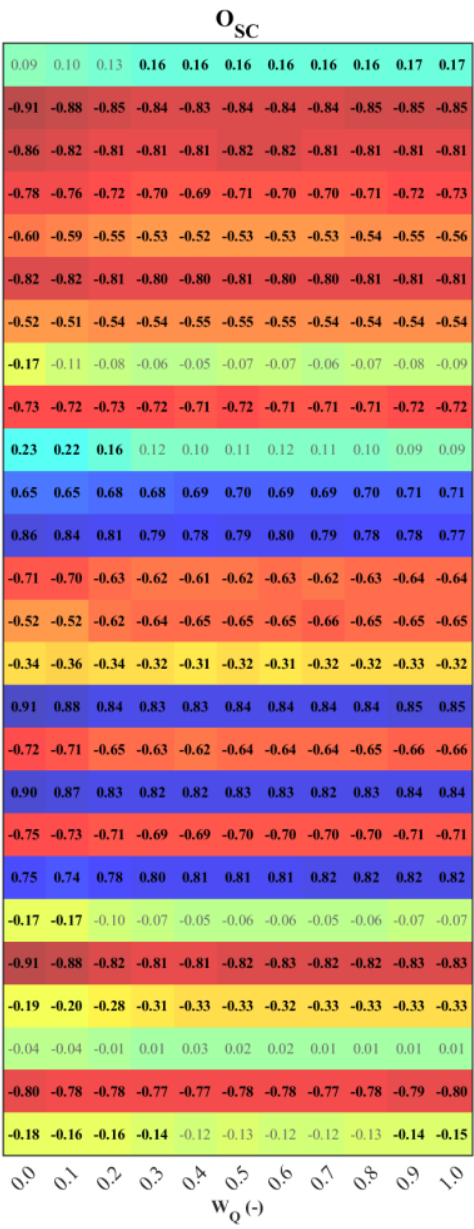

$\begin{array}{lllllllllll}-1.00 & -0.80 & -0.60 & -0.40 & -0.20 & 0.00 & 0.20 & 0.40 & 0.60 & 0.80 & 1.00\end{array}$

Figure S2: Correlation between catchment attributes (Table 1) and model performance, i.e. runoff (Eq. 2, left panel), soil moisture (Eq. 5, middle panel) and snow cover (Eq. 6, right panel), obtained from multiple objective calibration to satellite soil moisture (ASCAT), satellite snow cover (MODIS) and runoff (Var 3 of Table 5, SSM+SCM+runoff) in the validation period 2010-2014. Cool and warm colors represent positive and negative correlations, respectively. Bold print indicates significance with p-value lower than 0.05 . 


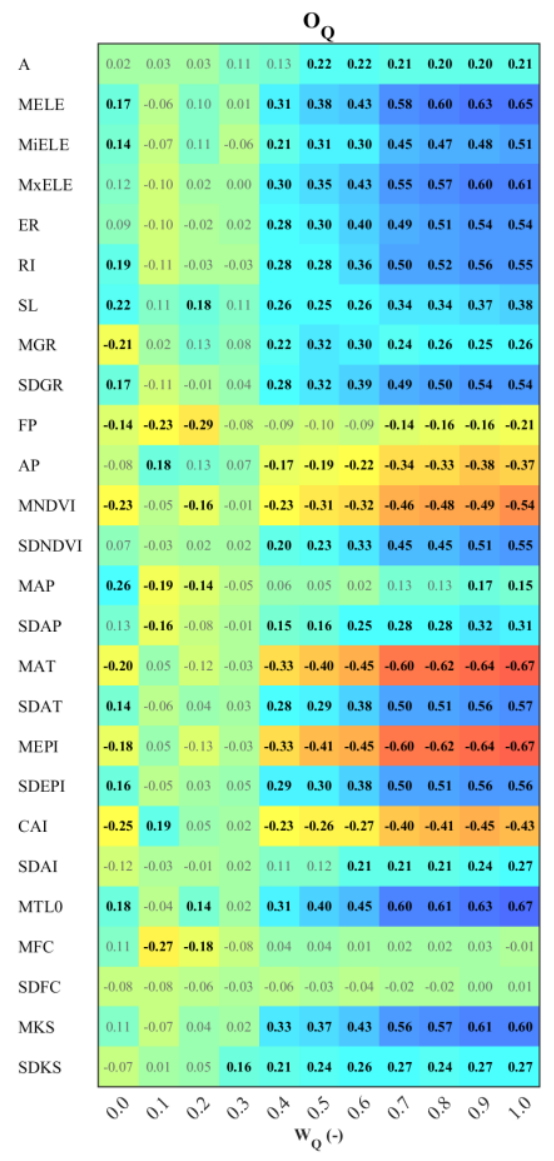

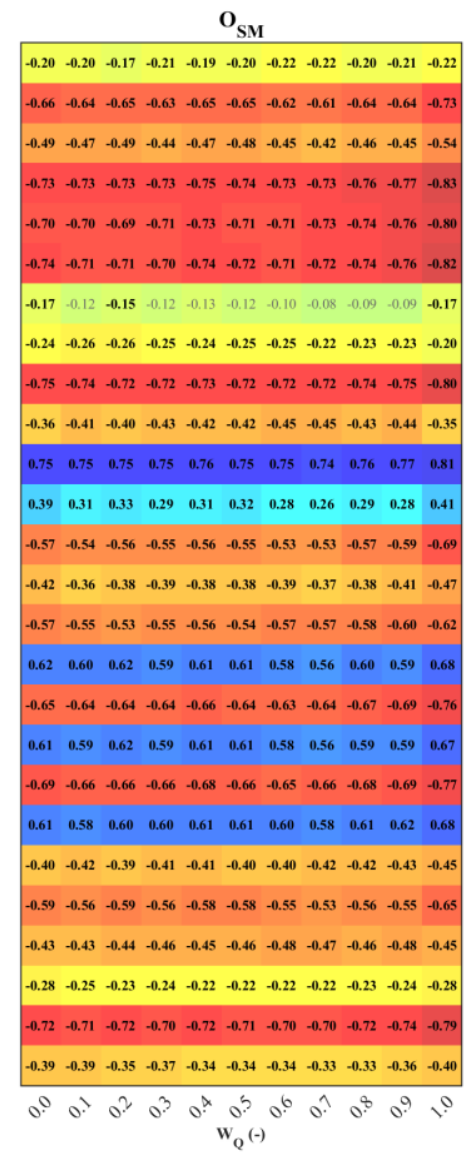

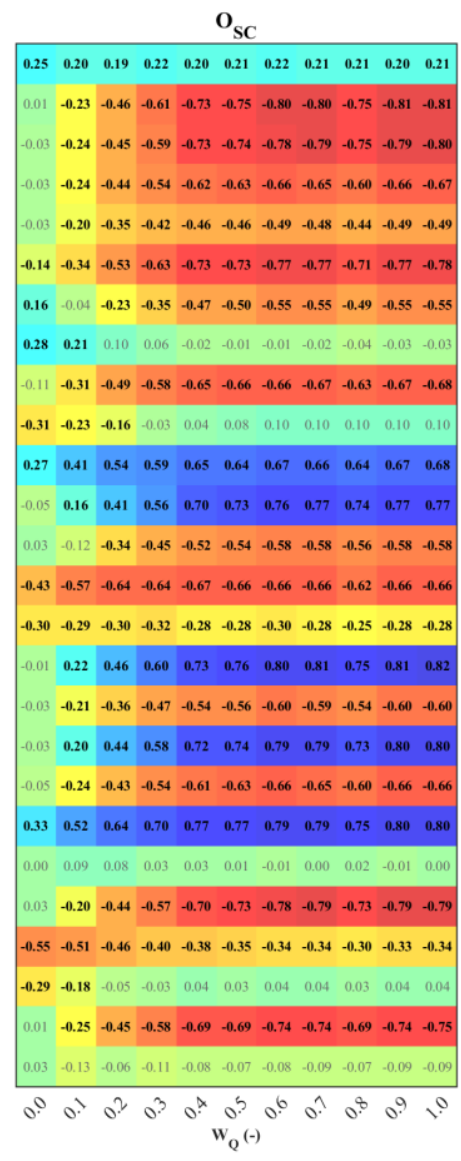

Correlation

$\begin{array}{lllllllllll}-1.00 & -0.80 & -0.60 & -0.40 & -0.20 & 0.00 & 0.20 & 0.40 & 0.60 & 0.80 & 1.00\end{array}$

Figure S3: Correlation between catchment attributes (Table 1) and model performance, i.e. runoff (Eq. 2, left panel), soil moisture (Eq. 5, middle panel) and snow cover (Eq. 6, right panel), obtained from multiple objective calibration to satellite soil moisture (ASCAT) and runoff (Var 1 of Table 4, SSM+runoff) in the calibration period 2000-2010. Cool and warm colors represent positive and negative correlations, respectively. Bold print indicates significance with p-value lower than 0.05 . 


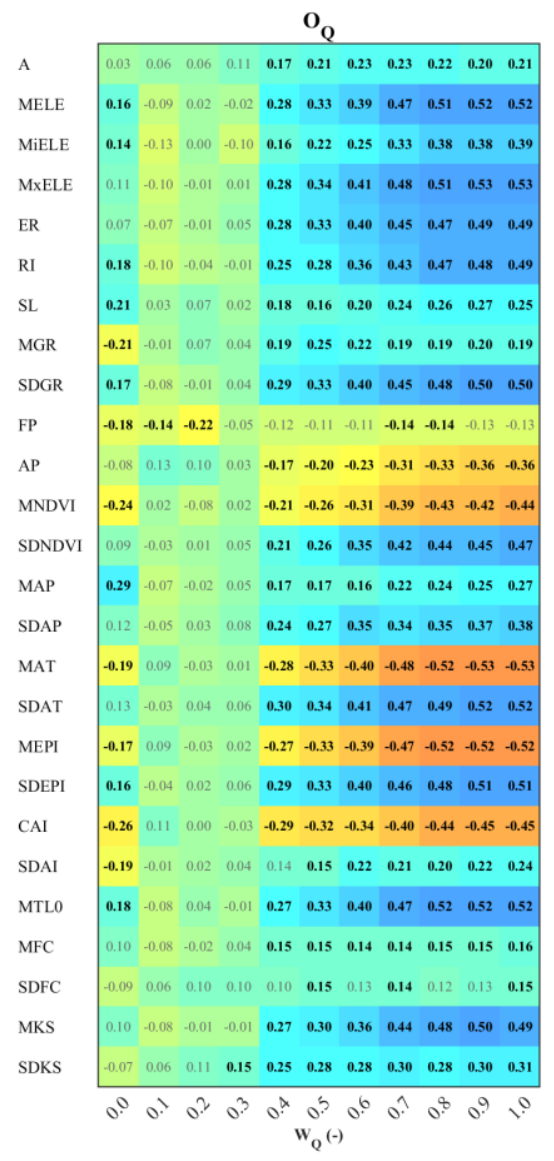

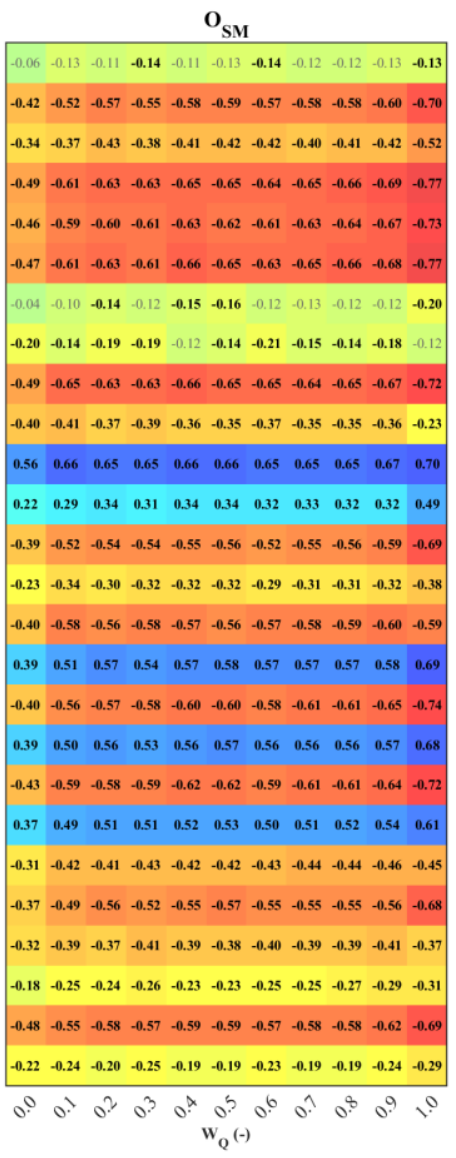

Correlation

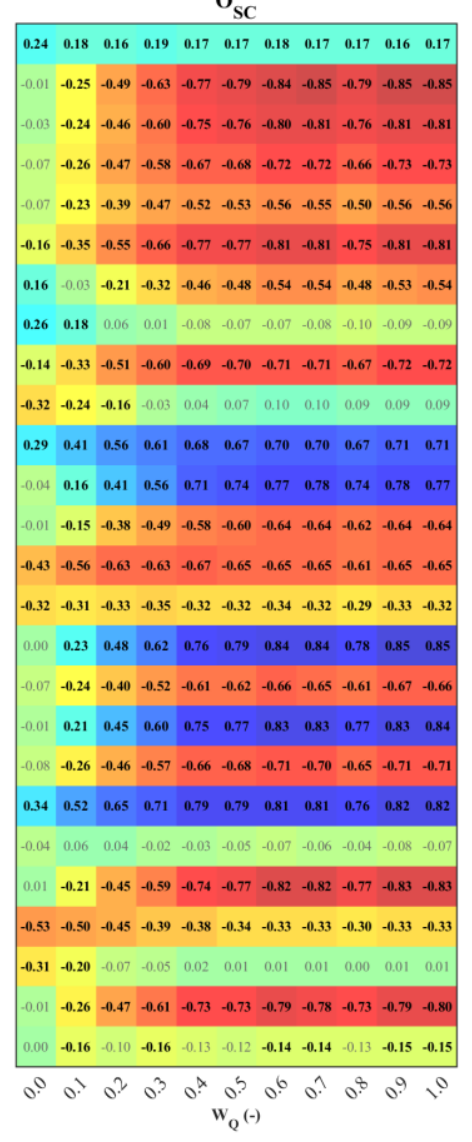

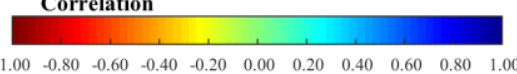

Figure S4: Correlation between catchment attributes (Table 1) and model performance, i.e. runoff (Eq. 2, left panel), soil moisture (Eq. 5, middle panel) and snow cover (Eq. 6, right panel), obtained from multiple objective calibration to satellite soil moisture (ASCAT) and runoff (Var 1 of Table 5, SSM+runoff) in the validation period 2010-2014. Cool and warm colors represent positive and negative correlations, respectively. Bold print indicates significance with p-value lower than 0.05 . 


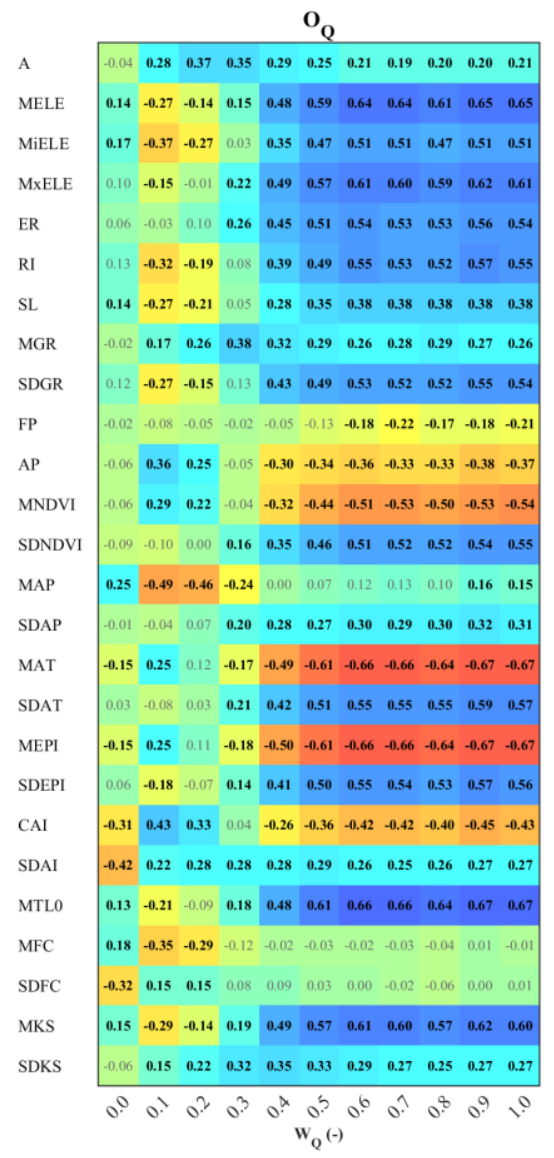

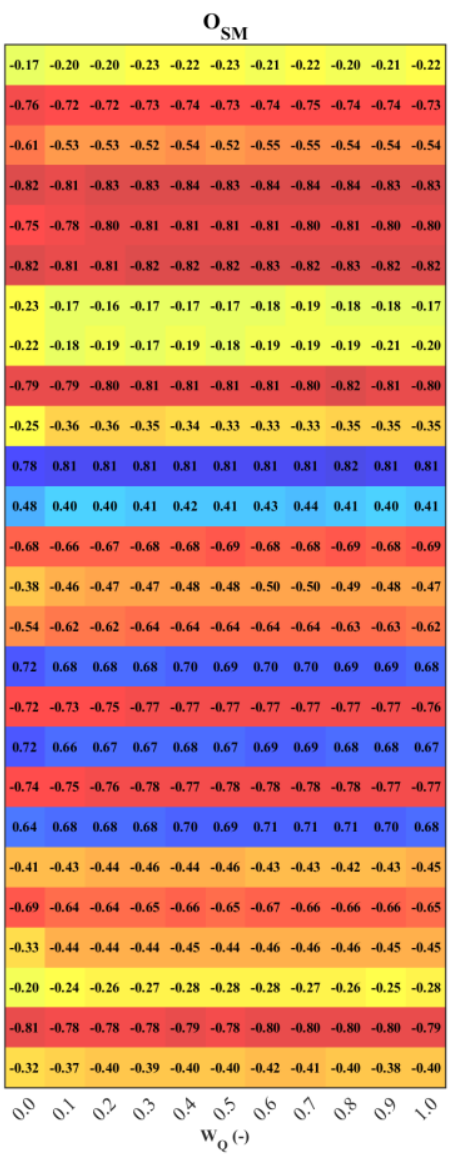

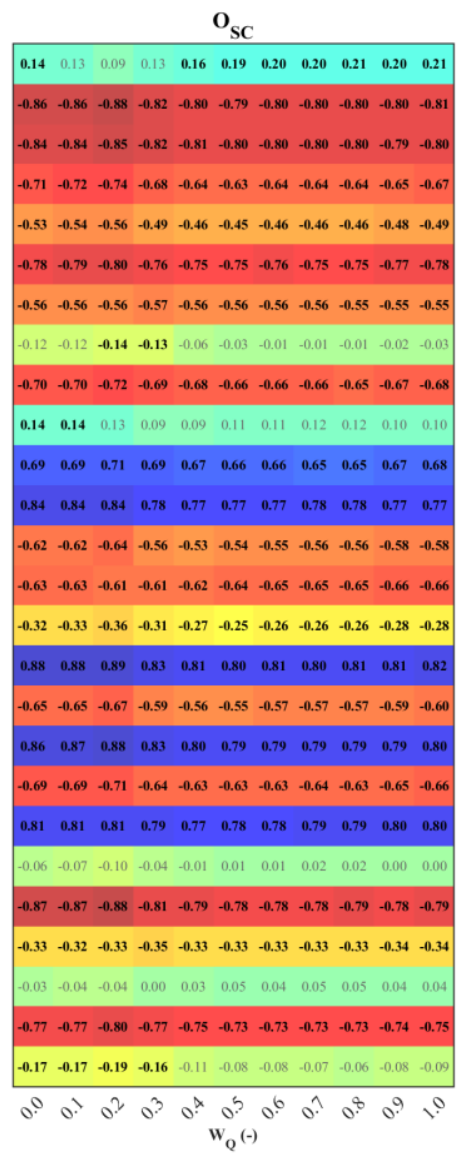

Correlation

$\begin{array}{lllllllllll}-1.00 & -0.80 & -0.60 & -0.40 & -0.20 & 0.00 & 0.20 & 0.40 & 0.60 & 0.80 & 1.00\end{array}$

Figure S5: Correlation between catchment attributes (Table 1) and model performance, i.e. runoff (Eq. 2, left panel), soil moisture (Eq. 5, middle panel) and snow cover (Eq. 6, right panel), obtained from multiple objective calibration to satellite snow cover (MODIS) and runoff (Var 2 of Table 4, SCM+runoff) in the calibration period 2000-2010. Cool and warm colors represent positive and negative correlations, respectively. Bold print indicates significance with p-value lower than 0.05 . 


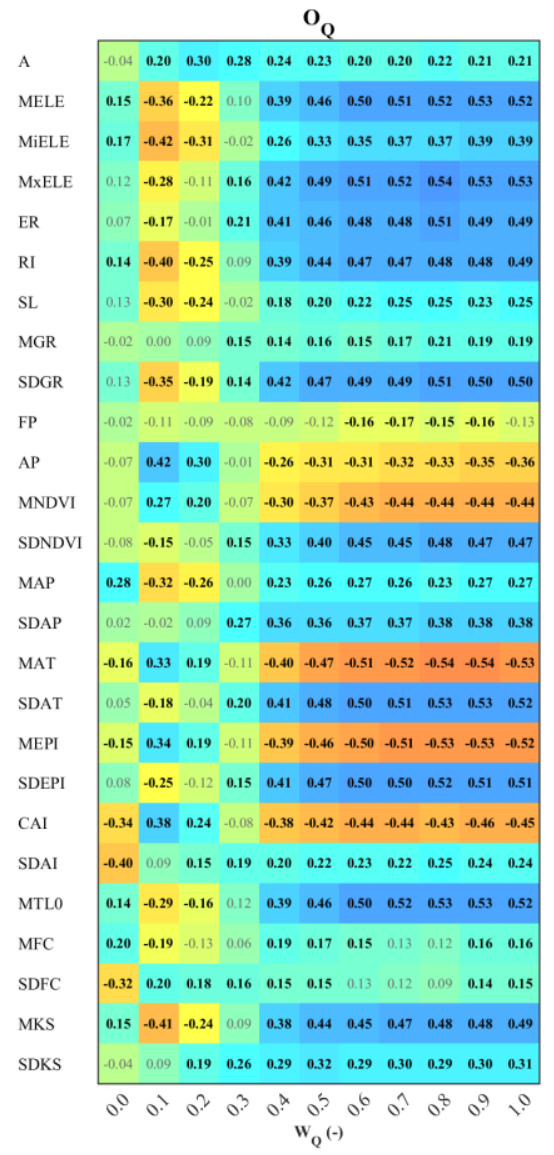

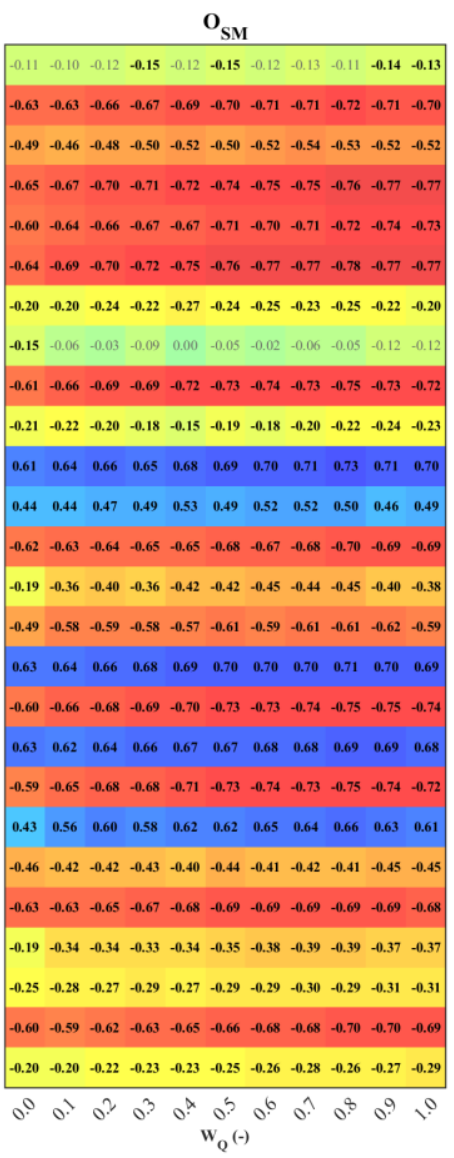

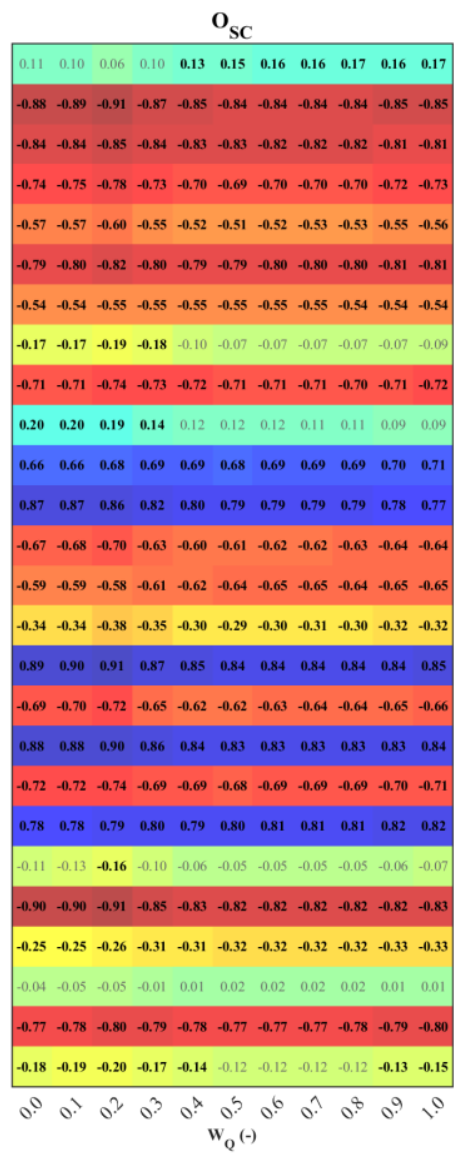

Correlation

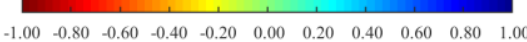

Figure S6: Correlation between catchment attributes (Table 1) and model performance, i.e. runoff (Eq. 2, left panel), soil moisture (Eq. 5, middle panel) and snow cover (Eq. 6, right panel), obtained from multiple objective calibration to satellite snow cover (MODIS) and runoff (Var 2 of Table 5, SSM+SCM+runoff) in the validation period 2010-2014. Cool and warm colors represent positive and negative correlations, respectively. Bold print indicates significance with p-value lower than 0.05 . 

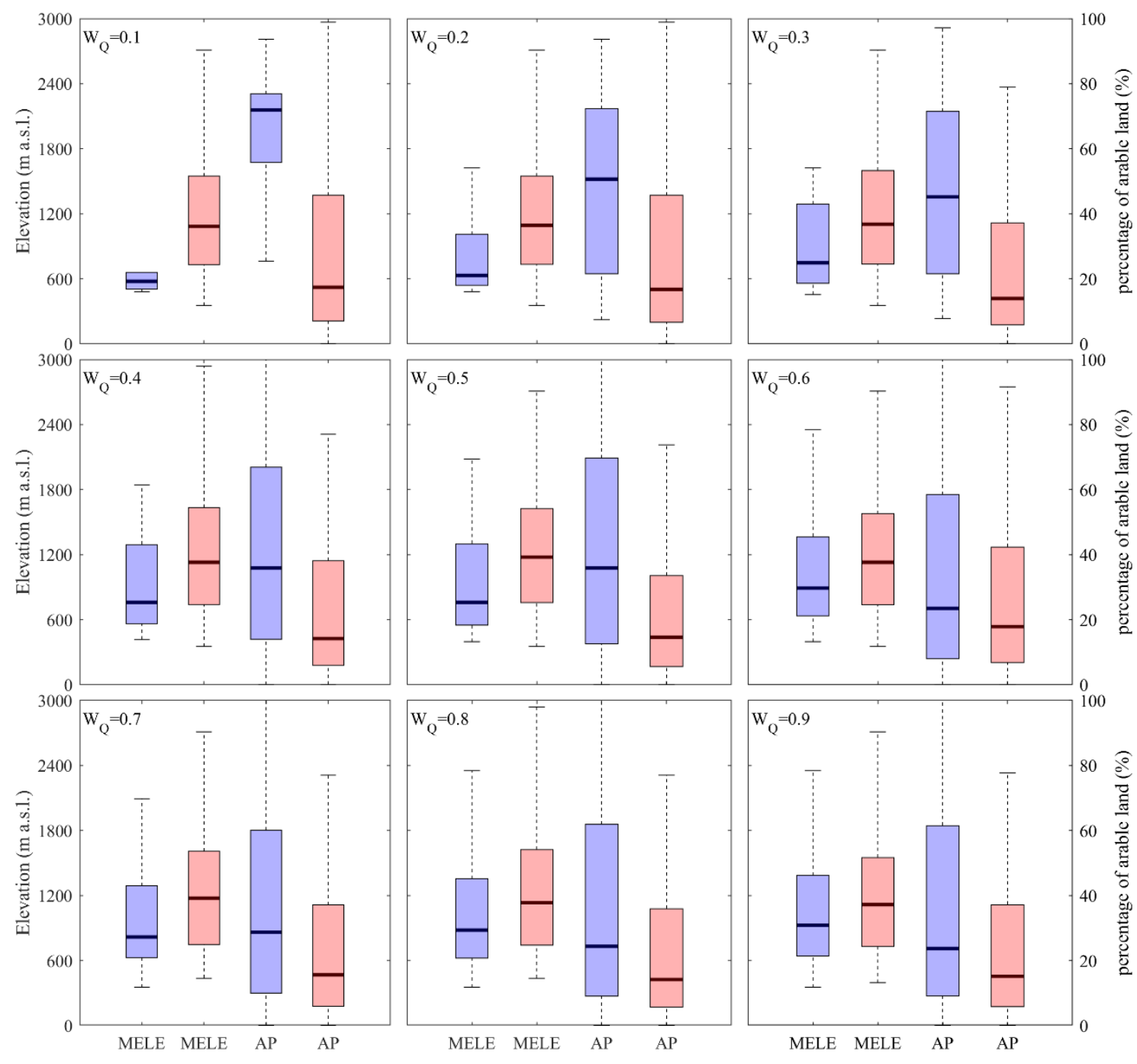

Figure S7: Distributions of mean catchment elevation (MELE) and percentage of arable land (AP) for the groups of catchments with (blue) and without (red) runoff model efficiency improvement in the validation period when including soil moisture and snow data in the calibration. 

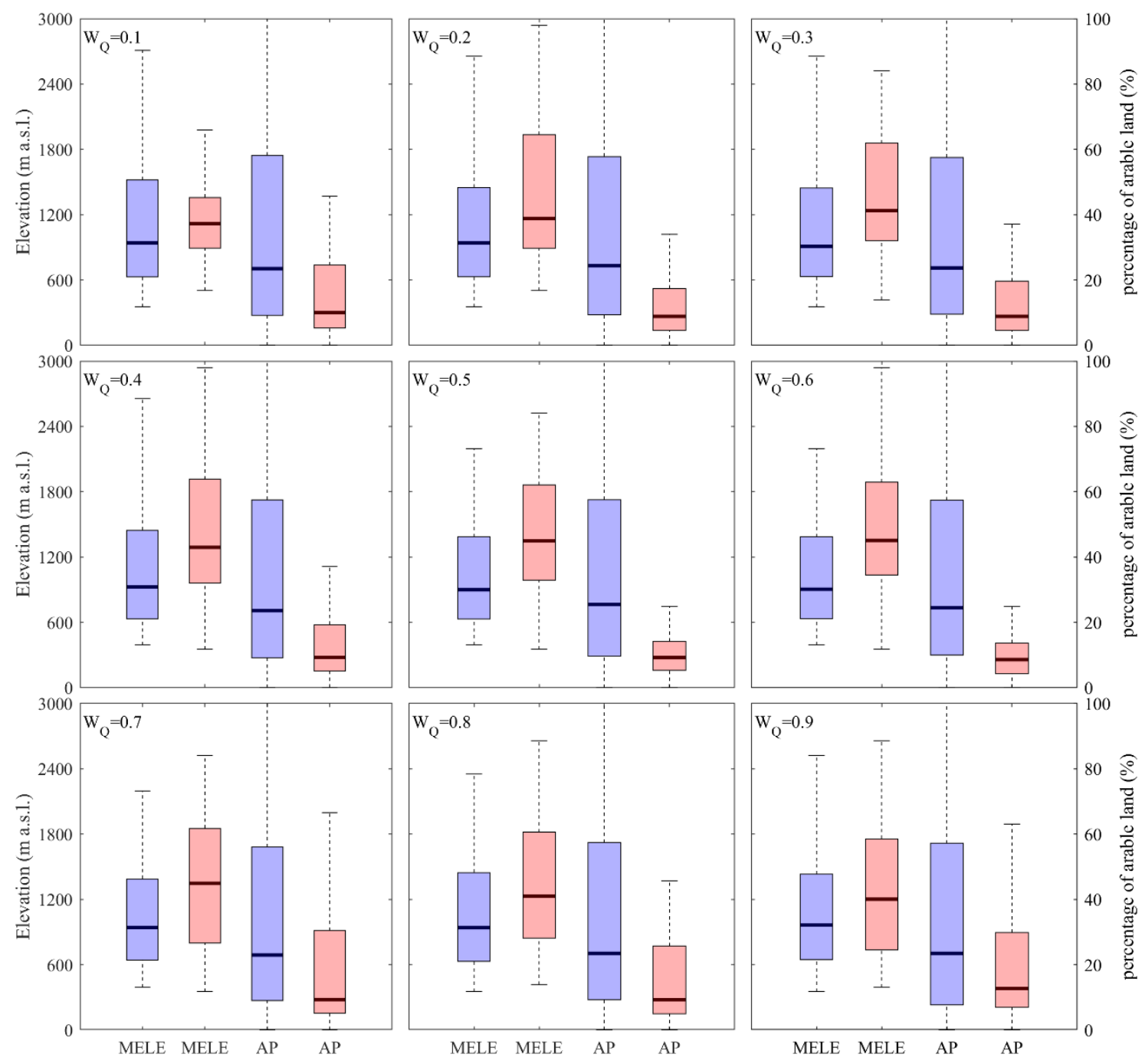

Figure S8: Distributions of mean catchment elevation (MELE) and percentage of arable land (AP) for the groups of catchments with (blue) and without (red) soil moisture model efficiency improvement in the validation period when including soil moisture and snow data in the calibration 
Table S1. Normalized Difference Snow Index (NDSI) threshold for snow cover mapping from Tong et al. (2020)

\begin{tabular}{|c|c|c|c|c|c|c|c|c|c|c|c|c|c|}
\hline \multicolumn{2}{|l|}{ Aqua } & Jan & Feb & Mar & Apr & May & Jun & Jul & Aug & Sep & Oct & Nov & Dec \\
\hline \multirow{3}{*}{$\begin{array}{l}\text { below } \\
900 \mathrm{~m} \\
\text { a.s.1. }\end{array}$} & non-forest & 0.36 & 0.34 & 0.36 & 0.67 & 0.98 & 0.97 & 0.89 & 0.96 & 0.84 & 0.67 & 0.43 & 0.41 \\
\hline & coniferous forest & 0.17 & 0.24 & 0.34 & 0.50 & 0.63 & 0.66 & 0.79 & 0.77 & 0.92 & 0.47 & 0.42 & 0.26 \\
\hline & other forest & 0.32 & 0.29 & 0.29 & 0.82 & 0.70 & 0.78 & 0.75 & 0.89 & 0.90 & 0.80 & 0.47 & 0.30 \\
\hline \multirow{3}{*}{$\begin{array}{l}\text { over } \\
900 \mathrm{~m} \\
\text { a.s.1. }\end{array}$} & non-forest & 0.22 & 0.18 & 0.28 & 0.49 & 0.67 & 0.91 & 0.89 & 0.91 & 0.71 & 0.43 & 0.45 & 0.26 \\
\hline & coniferous forest & 0.20 & 0.14 & 0.29 & 0.49 & 0.74 & 0.86 & 0.82 & 0.87 & 0.82 & 0.49 & 0.43 & 0.25 \\
\hline & other forest & 0.17 & 0.12 & 0.13 & 0.50 & 0.83 & 0.74 & 0.77 & 0.58 & 0.69 & 0.44 & 0.46 & 0.20 \\
\hline
\end{tabular}

\begin{tabular}{|l|l|l|l|l|l|l|l|l|l|l|l|l|l|}
\hline \multicolumn{2}{|l|}{ Terra } & Jan & Feb & Mar & Apr & May & Jun & Jul & Aug & Sep & Oct & Nov & Dec \\
\hline $\begin{array}{l}\text { below } \\
900 \mathrm{~m}\end{array}$ & non-forest & 0.32 & 0.30 & 0.37 & 0.57 & 0.74 & 0.78 & 0.82 & 0.85 & 0.82 & 0.52 & 0.41 & 0.36 \\
\cline { 2 - 14 } \begin{tabular}{l} 
a.s.l. \\
\cline { 2 - 14 }$y$
\end{tabular} & other forest & 0.22 & 0.19 & 0.29 & 0.86 & 0.78 & 0.64 & 0.78 & 0.74 & 0.65 & 0.65 & 0.40 & 0.31 \\
\hline \multirow{2}{*}{$\begin{array}{l}\text { over } \\
900 \mathrm{~m} \\
\text { a.s.l. }\end{array}$} & non-forest & 0.21 & 0.16 & 0.20 & 0.44 & 0.60 & 0.90 & 0.77 & 0.70 & 0.84 & 0.54 & 0.35 & 0.27 \\
\cline { 2 - 13 } & coniferous forest & 0.16 & 0.12 & 0.22 & 0.40 & 0.65 & 0.78 & 0.80 & 0.76 & 0.78 & 0.47 & 0.37 & 0.20 \\
\cline { 2 - 14 } & 0.10 & 0.11 & 0.10 & 0.17 & 0.53 & 0.16 & 0.26 & 0.69 & 0.67 & 0.31 & 0.31 & 0.22 \\
\hline
\end{tabular}

